\title{
The natural history of Echinorhynchus bothniensis Zdzitowiecki and Valtonen, 1987 (Acanthocephala) in a high Arctic lake
}

\author{
Raija-Liisa Aura $^{1}$, Daniel P. Benesh ${ }^{1,2}$, Risto Palomäki ${ }^{1}$ and E. Tellervo Valtonen \\ ${ }^{1}$ Department of Biological and Environmental Science, University of Jyväskylä, Finland; \\ ${ }^{2}$ Marine Science Institute, University of California, Santa Barbara, USA
}

\begin{abstract}
The acanthocephalan Echinorhynchus bothniensis Zdzitowiecki and Valtonen, 1987 differs from most other species in the genus Echinorhynchus Zoega in Müller, 1776 by infecting mysids (order Mysida) instead of amphipods (order Amphipoda) as intermediate hosts. Here we report on the occurrence of E. bothniensis in mysids (Mysis segerstralei Audzijonyte et Väinölä) and in its fish definitive hosts in a high Arctic lake. Out of 15907 sampled mysids, 4.8\% were infected with a mean intensity of 1.05 worms (range 1-5), although there was notable variation between samples taken in different years and sites. Larger mysids appear more likely to be infected. Of five fish species sampled, charr,Salvelinus alpinus (Linnaeus), and a benthic-feeding whitefish morph, Coregonus lavaretus (Linnaeus), were the most heavily infected (mean abundances of 80 and 15, respectively). The adult parasite population in fish exhibited a female-biased sex ratio $(1.78: 1)$. Although E. bothniensis is rather unique in infecting mysids, many aspects of its natural history mirror that of other acanthocephalan species.
\end{abstract}

Keywords: body size, Echinorhynchidae, intermediate host, Mysis, sex ratio, thorny-headed worms

Mysids (order Mysida) are known to be the intermediate hosts of some trophically-transmitted helminths (Smith and Lankester 1979, Prychitko and Nero 1983, Marcogliese and Burt 1993), including the acanthocephalans Echinorhynchus bothniensis Zdzitowiecki et Valtonen, 1987 and E. leidyi Van Cleave, 1924. These acanthocephalans differ from their close relatives by using mysids and not amphipods as intermediate hosts (Schmidt 1985). Valtonen et al. (1983) found that amphipods could be infected with eggs from female acanthocephalans from Baltic cod, Gadus morhua Linnaeus, which were later identified as E. gadi Zoega in Müller, 1776, whereas experimental infection of amphipods with eggs of acanthocephalans from smelt, $\mathrm{Os}_{\mathrm{s}}$ merus eperlanus (Linnaeus), failed.

This led Zdzitowiecki and Valtonen (1987) to describe the acanthocephalans from smelt in the northern part of the Bothnian Bay as a new species, E. bothniensis. Using allozymes, Väinölä et al. (1994) confirmed that E. bothniensis was genetically distinct from other species of Echinorhynchus Zoega in Müller, 1776 in northern Europe. Valtonen and Crompton (1990) found E. bothniensis in 14 fish species, although it matured in only six of these, most commonly smelt and burbot, Lota lota (Linnaeus). Here, we report the occurrence of E. bothniensis in its intermediate and definitive hosts in a high Arctic lake, Lake Pul- mankijärvi, with the goal of describing the natural history of this species and comparing it to other acanthocephalan species. A cursory description of some of these data were reported by Aura et al. (1990) in a conference abstract.

\section{MATERIALS AND METHODS}

\section{Study site}

Lake Pulmankijärvi is a high Arctic, oligotrophic lake on the border between Finland and Norway $\left(69^{\circ} 59^{\prime} \mathrm{N} ; 28^{\circ} 00^{\prime} \mathrm{E}\right)$. Its size is $12.1 \mathrm{~km}^{2}$, with a mean and maximum depth of 6.7 and $34 \mathrm{~m}$, respectively. Waters flow to the Arctic Ocean via the Pulmankijoki and Tenojoki rivers. It lies $14 \mathrm{~m}$ above sea level with steep shores. The most common fish species are pelagic- and benthic-feeding forms of whitefish, Coregonus lavaretus (Linnaeus), grayling, Thymallus thymallus (Linnaeus), three-spined stickleback, Gasterosteus aculeatus Linnaeus, minnow, Phoxinus phoxinus (Linnaeus), and, as a peculiarity, a flatfish, Platichthys flesus (Linnaeus), which migrates from the Arctic Ocean. Other fish species occurring in the lake are Arctic char, Salvelinus alpinus (Linnaeus), brown trout, Salmo trutta Linnaeus, salmon, S. salar Linnaeus, nine-spined stickleback, Pungitius pungitius (Linnaeus), pike, Esox lucius Linnaeus, perch, Perca fluviatilis Linnaeus, burbot and rarely eels, Anguilla anguilla (Linnaeus) (Niemelä and Hynninen 1983). 


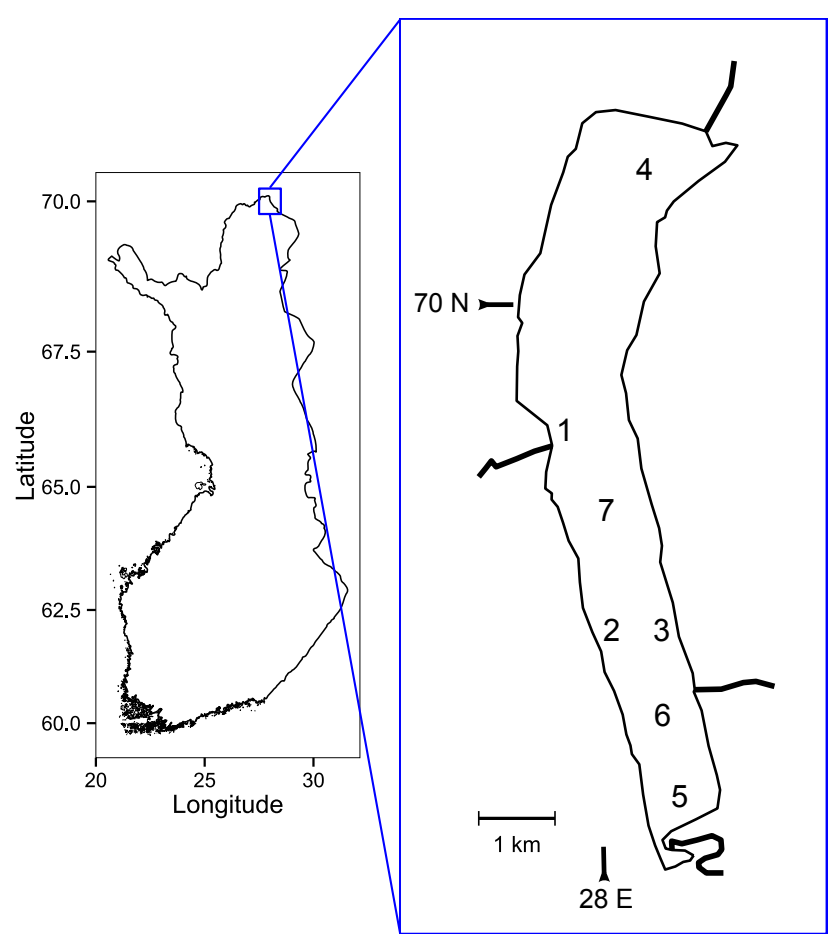

Fig. 1. Map of Lake Pulmankijärvi with sampling sites (right). The inset on the map of Finland (left) shows the location of the study lake. Site 7 is the deepest point in the lake (34 m).

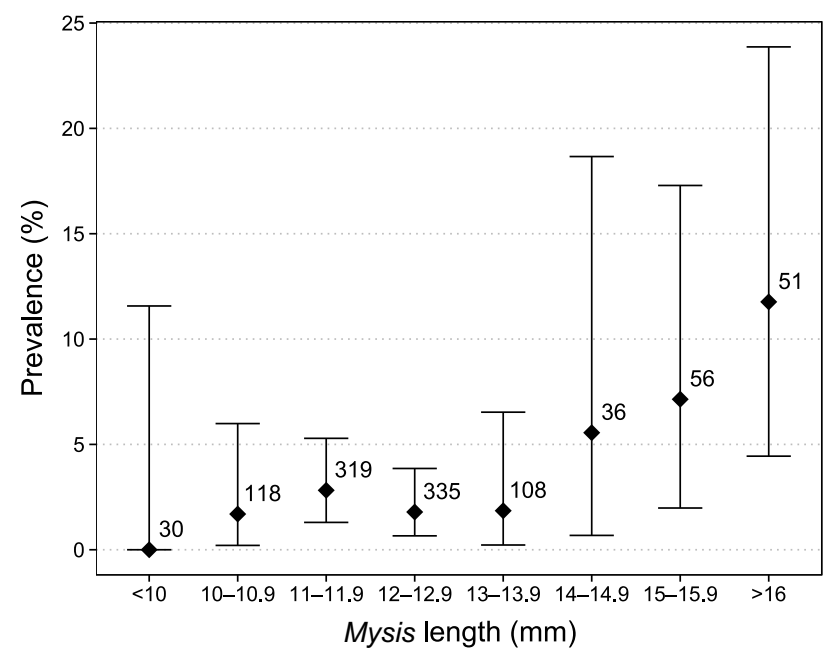

Fig. 2. The prevalence of Echinorhynchus bothniensis Zdzitowiecki and Valtonen, 1987 in mysids of different sizes collected in June 1989. Sample sizes in each group are indicated and bars represent the $95 \% \mathrm{CI}$.

\section{Sampling of intermediate hosts}

Mysis segerstralei Audzijonytė and Väinölä (formerly M. relicta Lovén, see Audzijonytė and Väinölä 2005) were collected in 1984, 1985, and 1989 from 7 sites in Lake Pulmankijärvi (Fig. 1, Table 1). Benthic samples were collected with a trawl net as well as an Ockelman-type bottom sledge (both having a mesh size of $0.6 \mathrm{~mm}$ ). The nets were pulled along the lake bottom for a few minutes to collect mysids. Additionally, bongo nets ( 2 connected sieve-nets with a height of $2 \mathrm{~m}$, an opening of $60 \mathrm{~cm}$ in diameter, and a mesh size of $0.3 \mathrm{~mm}$ ) were used to collect mysids from the water column at known depths, and a pull net (surface area
Table 1. Samples of Mysis segerstralei Audzijonytè et Väinölä taken from Lake Pulmankijärvi and examined for infection with Echinorhynchus bothniensis Zdzitowiecki et Valtonen, 1987.

\begin{tabular}{|c|c|c|c|c|c|c|}
\hline Sample & Sites & $\begin{array}{l}\text { Depth } \\
(\mathrm{m})\end{array}$ & $\mathrm{N}$ & $\begin{array}{c}\text { Prevalence } \\
(\%)\end{array}$ & Worms & $\begin{array}{c}\text { Max } \\
\text { intensity }\end{array}$ \\
\hline Jun 1984 & $1-3$ & $11-30$ & 470 & 0 & 0 & - \\
\hline $\begin{array}{l}\text { September- } \\
\text { October } 1984\end{array}$ & $1-3$ & $5-30$ & 1057 & 0.28 & 3 & 1 \\
\hline July 1985 & 4 & $5-15$ & 3220 & 4.66 & 160 & 5 \\
\hline July 1985 & 5 & $15-17$ & 2152 & 11.20 & 246 & 2 \\
\hline July 1985 & 6 & $25-30$ & 4099 & 5.03 & 220 & 4 \\
\hline July 1985 & 7 & 34 & 3046 & 3.18 & 100 & 2 \\
\hline June 1989 & 7 & 34 & 1053 & 2.94 & 32 & 1 \\
\hline Total & - & - & 15097 & 4.82 & 761 & 5 \\
\hline
\end{tabular}

$\mathrm{N}$ - number of mysids examined; worms - acanthocephalans recovered.

of $1 \mathrm{~m}^{2}$ and a mesh size of $0.4 \mathrm{~mm}$ ) was used to sample the entire water column. Mysids collected with different devices were combined to calculate infection parameters for one site at one time. The size of the mysids in the 1989 sample was measured to the nearest $1 \mathrm{~mm}$. Recovered acanthocephalans were stained using Grenacher borax carmine, dehydrated in an alcohol series, cleared in beechwood oil, and embedded in Canadian balsam. Subsamples of worms were sexed and measured.

\section{Sampling of fish}

In June 1989, five fish species were caught with gill-nets and frozen. The intestinal tract of thawed fish was examined later in the laboratory. Acanthocephalans were identified to species and females were recorded as non-gravid (just ovarian balls) or gravid (mature acanthors present). Terminology conforms to that proposed by Bush et al. (1997).

\section{RESULTS}

\section{Echinorhynchus bothniensis in mysids}

We found 761 individuals of E. bothniensis in 15097 Mysis segerstralei (Table 1). Prevalence varied between samples. From the near-coast sites sampled in 1984, only 3 infected mysids were collected $(0.2 \%)$, whereas a maximum prevalence of $11.2 \%$ was obtained at one site in 1985. Most of the infected mysids harboured a single worm (overall mean intensity $=1.05$ ); the maximum intensity was 5. In the 1989 sample, the prevalence of infection differed significantly between size groups (Chi-square test, $\left.\chi_{7}^{2}=21.78, \mathrm{P}=0.003\right)$, and appeared to increase in larger mysids (Fig. 2).

For 619 worms sexed in the 1985 samples, the male to female sex ratio was $1.14: 1$, which did not differ significantly from an equal sex ratio (Chi-square test, $\chi_{1}^{2}=2.72$, $\mathrm{P}=0.099)$. Female cystacanths $(\mathrm{n}=74$, mean $=4.59 \mathrm{~mm}$, range $=3.38-6.25 \mathrm{~mm})$ were longer than males $(\mathrm{n}=67$, mean $=3.53 \mathrm{~mm}$, range $=2.75-4.38 \mathrm{~mm}$ ). The sexual development of these cystacanths was relatively advanced. The females had up to 150 ovarian balls free in the body cavity (mean $=100, n=40$, range $=60-150)$. In male larvae, the average testis length was $0.43 \mathrm{~mm}(\mathrm{n}=64$, range $0.26-0.64$ $\mathrm{mm}$ ), which is only about $33 \%$ smaller than the typical testis size for adults in this population (Wayland 2013). 
Table 2. Infection of Echinorhynchus bothniensis Zdzitowiecki et Valtonen, 1987 in five fish species sampled in June 1989 from Lake Pulmankijärvi. The proportion of males, females with just ovarian balls (non-gravid), and females with at least some shelled acanthors (gravid) was calculated for each host except the flatfish.

\begin{tabular}{|c|c|c|c|c|c|}
\hline Fish species & $\begin{array}{l}\text { Fish length }(\mathrm{mm}) \\
(\mathrm{SD})\end{array}$ & $\mathrm{N}$ & Prevalence $(\%)$ & $\begin{array}{l}\text { Total worms } \\
\text { recovered }\end{array}$ & $\begin{array}{c}\text { Males : non-gravid females : } \\
\text { gravid females }(\%)\end{array}$ \\
\hline Coregonus lavaretus (Linnaeus) (pelagic)* & $156(17)$ & 36 & 8.3 & 6 & $50: 33: 17$ \\
\hline Coregonus lavaretus (Linnaeus) (benthic)* & $238(36)$ & 30 & 70 & 456 & $40: 35: 25$ \\
\hline Salvelinus alpinus (Linnaeus) & $189(51)$ & 9 & 100 & 721 & $33: 24: 43$ \\
\hline Thymallus thymallus (Linnaeus) & 238 & 4 & 25 & 3 & $67: 33: 0$ \\
\hline Platichthys flesus (Linnaeus) & 158 & 4 & 50 & 14 & - \\
\hline
\end{tabular}

*the mean number of gill rakers differs between pelagic- and benthic-feeding forms of whitefish and was 40 and 25 , respectively.

\section{Echinorhynchus bothniensis in fish}

Both of the two coregonids were infected, but E. bothniensis was far more common in the benthic-feeder (Table 2, mean abundance: 15.2 vs 0.2 ). Although only 9 char were examined, the high prevalence $(100 \%)$ and mean intensity of infection (80) suggests that this may be an important definitive host for E. bothniensis in Lake Pulmankijärvi. Mature females were also found in grayling and flounder (Table 2). The overall sex ratio of parasites collected from fish was significantly biased towards females (1.78 females for each male, Chi-square test, $\chi_{1}^{2}=92.9$, $\mathrm{P}<0.001)$.

\section{DISCUSSION}

Within the genus Echinorhynchus, E. bothniensis and the closely related E. leidyi are exceptional, using mysids instead of amphipods as intermediate hosts (Prychitko and Nero 1983, Valtonen et al. 1983). Ours is the first study on the ecology of E. bothniensis in its intermediate host. Prevalence was low overall (4.8\%) and typically just one worm was recovered per infected mysid. E.T. Valtonen (unpubl. data) observed a similar prevalence $(1.3 \%)$ and intensity of infection (1.1) in mysids ( $\mathrm{n}=1397)$ from Lake Keitele in central Finland, and Prychitko and Nero (1983) found E. leidyi at prevalences up to $3.6 \%$ in North American mysids. These prevalences are comparable to those for species of Echinorhynchus infecting amphipods (e.g. E. gadi: 0.8\% - Marcogliese 1994, 0.9\% - Benesh et al. 2015, E. salmonis Müller, 1784: 8.8\% - Nybelin 1924, 0.1\% - Amin 1978, 0.9\% - Okaka 1984, 0.4\% - Benesh et al. 2015, E. truttae Schrank, 1788: 2.3\% - Okaka 1984, 2.8\% - Lassiere 1989, 4.1\% - MacNeil et al. 2003, $1.3 \%$ - Dezfuli et al. 2008). Thus, it is not obvious that acanthocephalan transmission to and/or from mysids and amphipods differs substantially.

Prevalence in mysids varied between samples, but this might be attributable to spatial (differences between sites or depths) or temporal effects (differences between years). In any case, this variation could contribute to the aggregated distribution of adults in fish (Valtonen and Crompton 1990). We also found higher prevalence in larger mysids. An increase in infection with intermediate host size has been observed in other acanthocephalans (Liat and Pike 1980, Wilson and Hubschman 1985, Lagrue et al. 2007, Oliva et al. 2008, La Sala et al. 2012), although peak abundances in medium-sized hosts is perhaps the more common pattern (Hine and Kennedy 1974,
Muzzall 1978, 1982, Camp and Huizinga 1980, Brattey 1986, Brown and Pascoe 1989, Lagrue et al. 2007, Outreman et al. 2007, Rauque and Semenas 2007). A number of processes could result in higher prevalence in bigger mysids. For example, bigger mysids may be older and thus have had more time to be exposed to infection, or small, infected mysids might have higher mortality rates than large, infected mysids. An elevated mysid growth rate caused by E. bothniensis, such that infected mysids quickly become large, is also a possibility, but it seems less likely, given that acanthocephalans sometimes have little impact on intermediate host growth (Uznanski and Nickol 1980, Benesh and Valtonen 2007a).

In the intermediate host, females of $E$. bothniensis have well-developed ovarian balls and males have large testes, particularly relative to their body size, indicating that this species reaches an advanced state of maturity as larvae (Crompton 1985). Sexual size dimorphism is also clear in the intermediate host, which is common for species of Echinorhynchus - see Benesh and Valtonen (2007b). The sex ratio of $E$. bothniensis was slightly and non-significantly male-biased in mysids, but strongly female-biased in fish. This suggests that recruitment into and/or loss from each host may differ between the sexes. In acanthocephalans displaying seasonality, adult sex ratios often become more female-biased over the course of a season, suggesting that females survive longer than males (e.g. Tedla and Fernando 1970, Valtonen 1980, Brattey 1988, Lasee 1989). This probably explains the over-representation of females of E. bothniensis in our fish samples. Alternatively, the manipulation of host phenotype can also differ between male and female cystacanths (Benesh et al. 2009), hinting at the possibility of sex-specific transmission rates from intermediate to definitive host. However, the nearly equal sex ratio in larval E. bothniensis is not consistent with females having a substantially higher transmission rate out of mysids and into fish compared to males.

In Lake Pulmankijärvi, Arctic char and benthic-feeding coregonids were the main definitive hosts of E. bothniensis. This acanthocephalan was described from smelt (Zdzitowiecki and Valtonen 1987), but mature females have also been found in lampreys, burbot, flounder, and salmonids like trout and whitefish (Valtonen and Crompton 1990). Thus, it appears to have a wide definitive host range. The low abundance in plankton-feeding whitefish suggests that mysid consumption, rather than the host's phylogenetic affinities, is a key determinant of infection in fish. 
Väinölä et al. (1994), using allozymes, found that E. bothniensis from Lake Pulmankijärvi differed genetically from worms collected from two locations in the Baltic Basin (Bothnian Bay and Lake Keitele, Central Finland), although they did not consider the divergence sufficient to deem them separate species. Morphological differentiation between these two genetic groups of E. bothniensis is limited (Wayland 2013). The mysids found in these two areas have now been recognised as separate species (Audzijonytè and Väinölä 2005), which hints at co-evolution between these worms and their mysid hosts, although additional analyses would be needed to robustly test this hypothesis.

Acknowledgements. Thanks to David W.T. Crompton for initial discussions of these data. DPB gratefully acknowledges support from the German Research Foundation (BE 5336/1-1).

\section{REFERENCES}

AмiN O. 1978: On the crustacean hosts of larval acanthocephalan and cestode parasites in southwestern Lake Michigan. J. Parasitol. 64: 842-845.

AUdZIJONYTĖ A., VÄINÖLÄ R. 2005: Diversity and distributions of circumpolar fresh- and brackish-water Mysis (Crustacea: Mysida): descriptions of $M$. relicta Lovén, 1862, M. salemaai $\mathrm{n}$. sp., M. segerstralei $\mathrm{n}$. sp. and M. diluviana $\mathrm{n}$. sp., based on molecular and morphological characters. Hydrobiologia 544: 89-141.

Aura R.-L., Valtonen E.T., Andersin A.B. 1990: On the acanthocephalan infection in some glacial relict crustaceans in Finland. Ann. Zool. Fennici. 27: 245.

Benesh D.P., Aura R.-L., Andersin A.-B., Valtonen E.T. 2015: The occurrence of Echinorhynchus salmonis Müller, 1784 in benthic amphipods in the Baltic Sea. Folia Parasitol. 62: 052.

Benesh D.P., Seppälä O., Valtonen E.T. 2009: Acanthocephalan size and sex affect the modification of intermediate host colouration. Parasitology 136: 847-854.

Benesh D.P., Valtonen E.T. 2007a: Effects of Acanthocephalus lucii (Acanthocephala) on intermediate host survival and growth: implications for exploitation strategies. J. Parasitol. 93: 735-741.

Benesh D.P., Valtonen E.T. 2007b: Sexual differences in larval life history traits of acanthocephalan cystacanths. Int. J. Parasitol. 37: 191-198.

Brattey J. 1986: Life history and population biology of larval Acanthocephalus lucii (Acanthocephala: Echinorhynchidae) in the isopod Asellus aquaticus. J. Parasitol. 72: 633-645.

Brattey J. 1988: Life history and population biology of adult Acanthocephalus lucii (Acanthocephala, Echinorhynchidae). J. Parasitol. 74: 72-80.

Brown A.F., PAScoe D. 1989: Parasitism and host sensitivity to cadmium: an acanthocephalan infection of the freshwater amphipod Gammarus pulex. J. Appl. Ecol. 26: 473-487.

Bush A.O., Lafferty K.D., Lotz J.M., Shostak A.W. 1997: Parasitology meets ecology on its own terms: Margolis et al revisited. J. Parasitol. 83: 575-583.

Camp J.W., Huizinga H.W. 1980: Seasonal population interactions of Acanthocephalus dirus (Van Cleave 1931) in the creek chub, Semotilus atromaculatus, and isopod, Asellus intermedius. J. Parasitol. 66: 299-304.

Crompton D.W.T. 1985: Reproduction. In: D.W.T. Crompton and B.B. Nickol (Eds.), Biology of the Acanthocephala. Cambridge University Press, Cambridge, pp. 213-272.

Dezfuli B.S., Lui A., Giovinazzo G., Giari L. 2008: Effect of Acanthocephala infection on the reproductive potential of crustacean intermediate hosts. J. Invertebr. Pathol. 98: 116-119.

Hine P., Kennedy C. 1974: The population biology of the acanthocephalan Pomphorhynchus laevis (Müller) in the River Avon. J. Fish Biol. 6: 665-679.

Lagrue C., Kaldonski N., Perrot-Minnot M., Motreuil S., Bollache L. 2007: Modification of hosts' behavior by a parasite: field evidence for adaptive manipulation. Ecology 88: 2839-2847.

La Sala L.F., Perez A.M., Martorelli S.R. 2012: Epidemiology of acanthocephalan infections in crabs from the Bahía Blanca Estuary, Argentina. J. Helminthol. 86: 446-452.
LASEE B. 1989: Seasonal population dynamics and maturation of Neoechinorhynchus pungitius (Acanthocephala: Neoechinorhynchidae) infecting brook stickleback, Culaea inconstans, from Sioux Creek, Wisconsin, U.S.A. Can. J. Zool. 67: 590-595.

Lassiere O.L. 1989: The ecology of Neoechinorhynchus rutili (Acanthocephala) in Scottish freshwater lochs. PhD thesis, University of Glasgow, Glasgow, $311 \mathrm{pp}$.

Liat L.B., Pike A.W. 1980: The incidence and distribution of Profilicollis botulus (Acanthocephala), in the eider duck, Somateria mollissima, and in its intermediate host the shore crab, Carcinus. J. Zool. 190: 39-51.

MacNeil C., Fielding N.J., Hume K.D., Dick J.T., Elwood R.W., Hatcher M.J., Dunn A.M. 2003: Parasite altered micro-distribution of Gammarus pulex (Crustacea: Amphipoda). Int. J. Parasitol. 33: 57-64.

MarCogliese D. 1994: Aeginina longicornis (Amphipoda: Caprellidea), new intermediate host for Echinorhynchus gadi (Acanthocephala: Echinorhynchidae). J. Parasitol. 80: 1043-1044.

Marcogliese D., Burt M. 1993: Larval parasitic nematodes infecting marine crustaceans in eastern Canada. 2. Passamaquoddy Bay, New Brunswick. J. Helminthol. Soc. Wash. 60: 100-104.

Muzzall P.M. 1978: The host-parasite relationships and seasonal occurrence of Fessisentis friedi (Acanthocephala: Fessisentidae) in the isopod (Caecidotea communis). Proc. Helminthol. Soc. Wash. 45: 77-82.

Muzzall P.M. 1982: Parasites of Gammarus pseudolimnaeus and Hyalella azteca (Crustacea: Amphipoda) in three south-central Michigan localities. Proc. Helminthol. Soc. Wash. 49: 289-294.

Niemelä E., Hynninen P.R. 1983: [Management plan for fish stocks in the Utsjoki lake area.] Finnish Game and Fisheries Research Institute, Helsinki, Publication no. 8, 114 pp. (In Finnish.)

Nybelin O. 1924: Zur postembryonalen Entwicklungsgeschichte der Acanthcephalen II. Zool. Anz. 61: 190-193.

Окака C.E. 1984: Studies on the biology of Cyathocephalus truncatus (Pallas, 1781) (Cestoda: Spathebothridea) in its fish and crustacean hosts. PhD thesis, University of Leeds, Leeds, 259 pp.

Oliva M.E., Barrios I., Thatje S., Laudien J. 2008: Changes in prevalence and intensity of infection of Profilicollis altmani (Perry, 1942) cystacanth (Acanthocephala) parasitizing the mole crab Emerita analoga (Stimpson, 1857): an El Niño cascade effect? Helgol. Mar. Res. 62: S57-S62.

Outreman Y., Cezilly F., Bollache L. 2007: Field evidence of host size-dependent parasitism in two manipulative parasites. J. Parasitol. 93: 750-754.

Prychitko S., Nero R. 1983: Occurrence of the acanthocephalan Echinorhynchus leidyi (Van Cleave, 1924) in Mysis relicta. Can. J. Zool. 61: 460-462.

Rauque C.A., Semenas L. 2007: Infection pattern of two sympatric acanthocephalan species in the amphipod Hyalella patagonica (Amphipoda: Hyalellidae) from Lake Mascardi (Patagonia, Argentina). Parasitol. Res. 100: 1271-1276.

Schmidt G.D. 1985: Development and life cycles. In: D.W.T. Crompton and B.B. Nickol (Eds.), Biology of the Acanthocephala. Cambridge University Press, Cambridge, pp. 273-305. 
Smith J., Lankester M. 1979: Development of swim bladder nematodes (Cystidicola spp.) in their intermediate hosts. Can. J. Zool. 57: 1736-1744.

Tedla S., Fernando C. 1970: Some remarks on the ecology of Echinorhynchus salmonis Müller 1784. Can. J. Zool. 48: 317-321.

Uznanski R.L., Nickol B.B. 1980: Parasite population regulation - lethal and sublethal effects of Leptorhynchoides thecatus (Acanthocephala, Rhadinorhynchidae) on Hyalella azteca (Amphipoda). J. Parasitol. 66: 121-126.

VÄInÖlä R., VALtonen E., Gibson D. 1994: Molecular systematics in the acanthocephalan genus Echinorhynchus (sensu lato) in northern Europe. Parasitology 108: 105-114.

VAltonen E.T. 1980: Metechinorhynchus salmonis (Müller, 1780) (Acanthocephala) as a parasite of the whitefish in the Bothnian Bay. II. Sex ratio, body length and embryo development in relation to season and site in intestine. Acta Parasitol. Pol. 27: 301-307.

Received 23 April 2015
Valtonen E.T., Crompton D.W.T. 1990: Acanthocephala in fish from the Bothnian Bay, Finland. J. Zool. 220: 619-639.

Valtonen E.T., van Maren M.J., Timola O. 1983: A note on the intermediate hosts of Echinorhynchus gadi Zoega, in Müller (Acanthocephala) in the Baltic Sea. Aquil. Ser. Zool. 22: 93-97.

WAYLAND M.T. 2013: Morphological variation in Echinorhynchus truttae Schrank, 1788 and the E. bothniensis Zdzitowiecki \& Valtonen, 1987 species complex from freshwater fishes of northern Europe. Biodivers. Data J. 1: e975.

Wilson B., Hubschman J. 1985: Host-parasite relationships of Tanaorhamphus longirostris (Acanthocephala: Neoechinorhynchidae) in the intermediate host, Diaptomus pallidus (Crustacea: Copepoda). Proc. Helminthol. Soc. Wash. 52: $71-75$.

Zdzitowiecki K., Valtonen E.T. 1987: Description of Echinorhynchus bothniensis sp. n. (Acanthocephala), a parasite of smelt Osmerus eperlanus L. in Bothian Bay. Acta Parasitol. Pol. 32: $233-238$.

Cite this article as: Aura R.-L., Benesh D.P., Palomäki R., Valtonen E.T. 2015: The natural history of Echinorhynchus bothniensis Zdzitowiecki and Valtonen, 1987 (Acanthocephala) in a high arctic lake. Folia Parasitol. 62: 051. 